\title{
Does Bile Salt-Stimulated Lipase Affect Cholesterol Uptake When Bound to Rat Intestinal Mucosa In Vitro?
}

\author{
HELÉN FÄLT, OLLE HERNELL, AND LARS BLÄCKBERG \\ Department of Medical Biosciences, Physiological Chemistry [H.F., L.B.], Department of Clinical \\ Sciences, Pediatrics [H.F., O.H.], Umeå University, Umeå, Sweden
} \begin{abstract}
ABST
Bile salt-stimulated lipase (BSSL), or carboxyl ester lipase, is
a constituent of exocrine pancreatic secretion and, in some species, including humans, also of milk. BSSL has been suggested to have a direct effect on intestinal uptake of dietary cholesterol besides being the key enzyme in the hydrolysis of fat-soluble vitamins and cholesterol esters. Furthermore, an intestinal heparin-containing receptor for the enzyme has been implicated. If BSSL promotes dietary cholesterol utilization, this might be of particular importance in the neonatal period, which is characterized by a high need of cholesterol for membrane synthesis. We have studied binding of BSSL to intestinal membranes in vitro and if such binding affects the uptake of cholesterol. BSSL bound avidly to rat intestinal microvesicle mem-
\end{abstract} $\sqrt{1}$

Human milk provides the preterm newborn infant with conditionally essential LCPUFA of the n-6 and n-3 series for incorporation into membrane lipids, particularly of the brain, which is rapidly growing during the last trimester of pregnancy and first year of extrauterine life (1-4). LCPUFA have until recently not been added to infant formulas, but only their precursor fatty acids, linoleic acid (18:2n-6) and $\alpha$-linolenic acid (18:3n-3), respectively $(1,5)$. Human milk is also rich in cholesterol, another lipid constituent of structural importance for cell membrane formation. Whether formulas should be supplemented also with cholesterol to meet the level of human milk is controversial. Breast-fed infants do have higher serum cholesterol concentration than infants fed conventional formulas, which are not supplemented with cholesterol, but whether that is beneficial or not in the short- or long-term perspective is not known (6).

Received June 29, 2001; accepted January 29, 2002.

Correspondence: Helén Fält, Licentiate of Medical Science, Department of Clinical Sciences, Pediatrics, Umeå University, SE-901 87 Umeå, Sweden; e-mail: helen.falt@pediatri.umu.se

Supported by the Swedish Medical Research Council (19X-05708), Västerbotten County Council, AstraZeneca AB, and the Faculty of Medicine and Odontology, Umeå University.

DOI: 10.1203/01.PDR.0000030878.20888.12 branes and the binding was inhibited by addition of free heparin or heparin fragments. In this model system, we could not demonstrate any effect of BSSL on cellular uptake of free cholesterol. However, if esterified rather than free cholesterol was present in the incubation, hydrolysis by BSSL was the rate-limiting step in cellular cholesterol uptake. We therefore conclude that BSSL is important for utilization of dietary cholesterol only by hydrolyzing cholesterol esters and not by acting as a transport protein.

(Pediatr Res 52: 509-515, 2002)
BSSL, bile salt-stimulated lipase (EC 3.1.1.3)
LCPUFA, long-chain polyunsaturated fatty acids

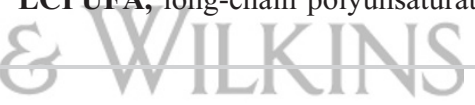

The molecular mechanism regulating intestinal cholesterol absorption is poorly understood. There is some evidence to suggest that transport proteins are involved (7-9). It has been advocated that secreted pancreatic proteins, e.g. BSSL and pancreatic colipase-dependent lipase bind to a receptor, or receptor-like structure, on enterocytes and, when bound, mediate absorption of cholesterol and FFA, respectively (10-12). Further, binding to the tentative receptor seems to involve interaction with heparin or a heparin-like structure. If so, BSSL would have a dual function, one being to hydrolyze acylglycerols, esterified fat-soluble vitamins, and sterol esters present in intestinal contents, and the other to serve as a transport protein of free cholesterol into the enterocytes. Although studies have shown that diversion of exocrine pancreatic secretion from the intestine markedly reduces cholesterol absorption and serum cholesterol levels (13), more recent studies using gene-targeted mice disrupting the BSSL gene support the role of BSSL in intestinal hydrolysis of cholesterol esters but do not support its role as a cholesterol transporter $(14,15)$. Studies in vitro using cell culture systems (Caco-2 cells) have also given conflicting results with respect to BSSL being a cholesterol transporter $(11,16-18)$. The aim of this study was therefore to clarify the role for BSSL in hydrolysis of cholesterol esters and transport 
of free cholesterol in a model system in vitro using rat microvesicle membranes.

\section{MATERIALS AND METHODS}

Standard heparin $(5000 \mathrm{IU} / \mathrm{mL})$ was from Löwens, Malmö, Sweden. Low-molecular-weight heparin fragments varying in chain length were prepared from porcine intestinal mucosa as described $(19,20)$, and were a generous gift from Dr. Per Østergaard, Novo Nordisk, Denmark. Cholate (sodium salt) and L- $\alpha$-phosphatidyl choline from egg yolk were from Sigma Chemical St. Louis, MO, U.S.A. $\left[1 \alpha, 2 \alpha(\mathrm{n})-{ }^{3} \mathrm{H}\right]$-cholesterol (49.0 Ci/mol) was from Amersham Pharmacia Biotech UK, Ltd., Little Chalfont, Buckinghamshire, U.K., and cholesteryl$4-{ }^{14} \mathrm{C}$-oleate $(53.1 \mathrm{Ci} / \mathrm{mol})$ from PerkinElmer Life Science Products, Boston, MA, U.S.A.

\section{Enzyme Preparation}

BSSL was purified from human milk as described (21). After lyophilization, the purified enzyme was dissolved in 10 $\mathrm{mM}$ Tris-Cl, $\mathrm{pH}$ 7.4. A recombinant variant of human BSSL (variant B), lacking all the proline-rich, O-glycosylated repeats was produced and purified as described previously $(22,23)$. Iodination of BSSL was performed using lactoperoxidase and glucose oxidase (24). The radiolabeled enzyme was purified from free ${ }^{125} \mathrm{I}$ by gel filtration on a G-25 column followed by heparin-Sepharose chromatography.

Catalytic activity of native BSSL and variant B were determined as described (21), using long-chain triacylglycerol emulsified with gum arabic as substrate.

\section{Preparation of Antibodies}

Polyclonal antibodies against purified human BSSL were raised in rabbits. The Ig were purified on Protein A-Sepharose. Fab-fragments were prepared by dissolving $0.5 \mathrm{mg}$ purified Ig in $2 \mathrm{~mL} 5 \mathrm{mM} \mathrm{NaH}{ }_{2} \mathrm{PO}_{4}, \mathrm{pH} 8.0$, and adding $50 \mu \mathrm{L}$ of EDTA $(26 \mathrm{mg} / \mathrm{mL})$ and $50 \mu \mathrm{L}$ cystein $(63.2 \mathrm{mg} / \mathrm{mL})$. Ten micrograms of papain (Sigma Chemical) was then added to the mixture, which was incubated for $4 \mathrm{~h}$ at $37^{\circ} \mathrm{C}$. The incubation was stopped by dialysis against $10 \mathrm{mM}$ phosphate buffer, $\mathrm{pH} 7.4$, containing $0.15 \mathrm{M} \mathrm{NaCl}$. The fragments were separated on Protein A-Sepharose and the purity checked by SDS-PAGE.

\section{Preparation of Vesicles}

Phospholipid cholesterol/cholesterol ester vesicles ("donor vesicles"). Phospholipid sterol-containing vesicles were prepared essentially as described by Lopez-Candales et al. (11). ${ }^{3} \mathrm{H}$-cholesterol (3-5 $\mu \mathrm{Ci}$ ) or ${ }^{14} \mathrm{C}$-cholesteryl oleate $(3-5 \mu \mathrm{Ci})$ was mixed with $0.15 \mathrm{~mL} 1.0 \mathrm{mM}$ phosphatidyl choline. The solvents were evaporated under nitrogen. Three milliliters 10 $\mathrm{mM}$ Tris-Cl, $\mathrm{pH} 7.4$, was added to each suspension, followed by sonication for $10 \mathrm{~min}$ in intervals of $4 \mathrm{~s}$ with a MSE Soniprep 150 sonifier (SANYO, Loughborough, U.K.). Below these vesicles are referred to as donor vesicles.

Intestinal membrane microvesicles. Brush border membrane microvesicles were prepared from the small intestine of male Sprague Dawley rats (Möllegaard, Ejby, Denmark) weighing between 200 and $250 \mathrm{~g}$. The rats were kept on a regular diet, but were fasted overnight before preparation. Vesicles were prepared according to Davidson and Lonnerdal (25) using a Teflon-in-glass homogenizer. Protein concentrations of the initial mucosal homogenate and the purified membrane microvesicles were determined using the bicinchoninic acid (BCA) assay (Bio-Rad, Hercules, CA, U.S.A.) at $37^{\circ} \mathrm{C}$, with BSA as standard. Enrichment of vesicles was assessed by a $7.5 \pm 2.4$ (mean $\pm \mathrm{SD}$ ) -fold increase of sucrase activity over that of the original homogenate. Sucrase activity was measured as described (26). The preparations contained $3.4 \pm 1.7 \mathrm{mg}$ of protein per milliliter and $2.5 \pm 1.1$ units sucrase activity per milliliter. Below these vesicles are referred to as membrane microvesicles.

Trypsination of membrane microvesicles. Rat membrane microvesicles $\left(2.5 \mathrm{mg}\right.$ of protein) were incubated at $37^{\circ} \mathrm{C}$ with $2 \%(\mathrm{wt} / \mathrm{wt}$ ) trypsin (TPCK-treated, Sigma Chemical). After 30 $\mathrm{min}$, another $2 \%(\mathrm{wt} / \mathrm{wt})$ of trypsin was added and the incubation continued for $30 \mathrm{~min}$. To interrupt the reaction, $0.25 \mathrm{~mL}$ aprotinin $(10,000 \mathrm{KIE} / \mathrm{mL}$ Trasylol, Bayer AG, Leverkusen, Germany) was added, the digest centrifuged, and the pellet resuspended in $0.54 \mathrm{~mL} 10 \mathrm{mM}$ Tris-Cl, $\mathrm{pH} 7.4$.

Trypsination removed more than $60 \%$ of membrane (vesicle) protein when visualized by SDS-PAGE (data not shown).

\section{Binding of BSSL to Membrane Microvesicles}

Rat membrane microvesicles ( $0.1 \mathrm{mg}$ of protein) were added to a total volume of $0.1 \mathrm{~mL} 10 \mathrm{mM}$ Tris-Cl, $1 \% \mathrm{BSA}, \mathrm{pH}$ 7.4. ${ }^{125} \mathrm{I}-\mathrm{BSSL}$ and other compounds were added as indicated in the respective figure legends. After $45 \mathrm{~min}$ at $37^{\circ} \mathrm{C}$, the incubations were stopped by centrifugation at $11,600 \times g, 4^{\circ} \mathrm{C}$ for 15 min. The pelleted microyesicles were washed three times with $0.1 \mathrm{~mL}$ of $10 \mathrm{mM}$ Tris-Cl, $\mathrm{pH} 7.4$, and the final pellet fractions and the supernatants were collected separately for determination of radioactivity.

To test the effect of heparin on enzyme binding, rat membrane microvesicles were incubated with $0.2 \mu \mathrm{g}$ of native ${ }^{125} \mathrm{I}$-BSSL or ${ }^{125} \mathrm{I}$-variant B in $10 \mathrm{mM}$ Tris-Cl, pH 7.4, with or without increasing concentrations of standard heparin.

\section{Incorporation of Cholesterol into Membrane Microvesicles}

Labeled cholesterol donor vesicles (containing 1 pmol ${ }^{3} \mathrm{H}$-cholesterol) or labeled cholesterol ester donor vesicles (containing $0.5 \mathrm{nmol}{ }^{14} \mathrm{C}$-cholesterol ester) were added to rat membrane microvesicles $(0.1 \mathrm{mg}$ of protein) suspended in $0.1 \mathrm{~mL}$ buffer. Various compounds were added, as indicated in the respective tables and figure legends, and the mixtures incubated, with or without $\mathrm{BSSL}$, at $37^{\circ} \mathrm{C}$, for the times indicated in the legends to Figure 1-5. After incubation, the membrane microvesicles were separated from donor vesicles by centrifugation at $11,600 \times g, 4^{\circ} \mathrm{C}$ for 15 min. In control experiments, $<1 \%$ of donor vesicles was pelleted. More than $90 \%$ of microvesicles were pelleted regardless of cholesterol content. The pelleted membrane microvesicles were washed three times as described above, resuspended in buffer, and taken to radioactivity determina- 

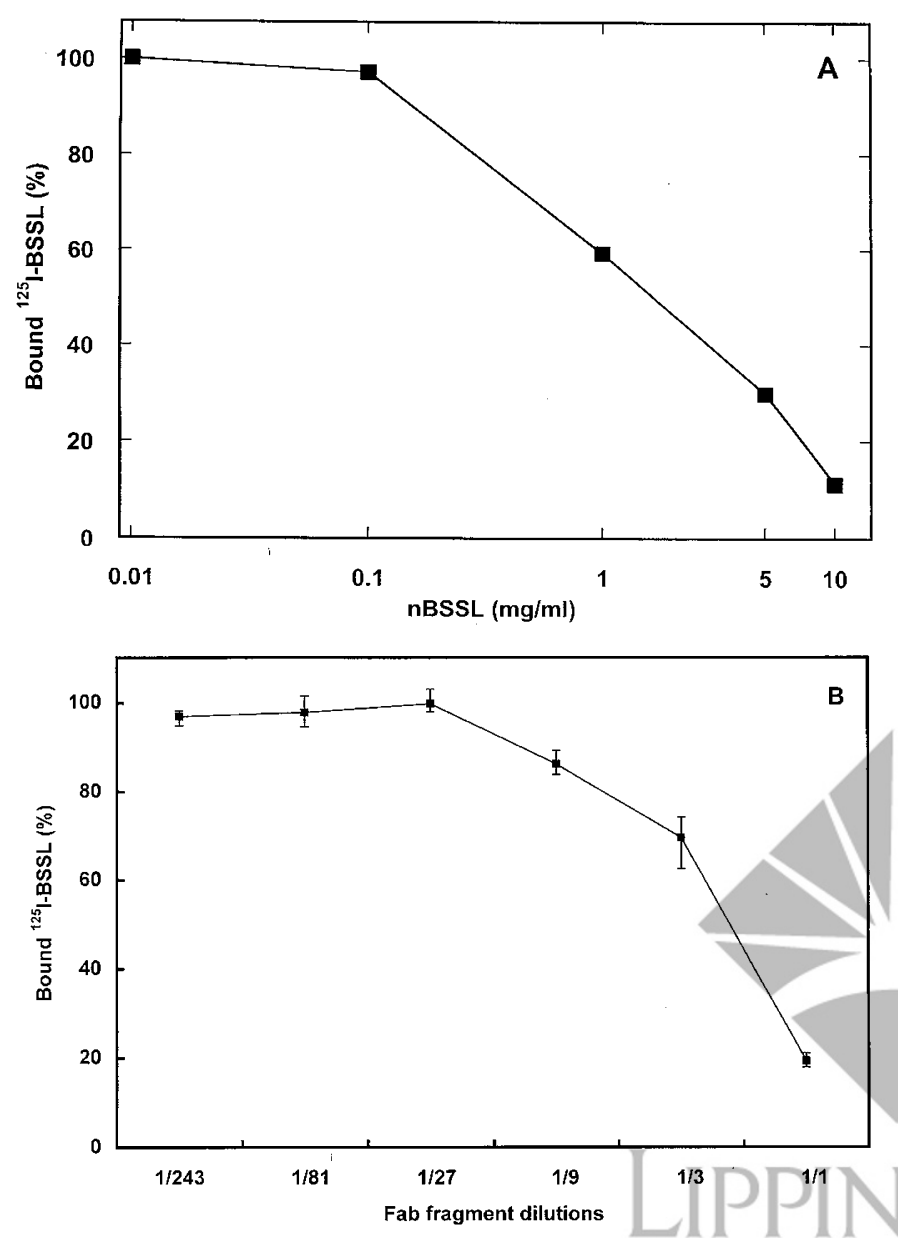

Figure 1. Effect of unlabelled BSSL and of polyclonal antibodies to BSSL on binding to membrane microvesicles. (A) Membrane microvesicles were incubated, as described in "Materials and Methods," with $0.4 \mu \mathrm{g}{ }^{125} \mathrm{I}$-BSSL. For assessment of nonspecific binding increasing amounts of unlabelled enzyme (BSSL) was added. Values are expressed as percent of bound enzyme in the absence of unlabelled enzyme. The figure represents one of several typical experiments. $(B){ }^{125} \mathrm{I}$-BSSL $(0.04 \mu \mathrm{g})$ and increasing concentrations of Fabfragments of polyclonal rabbit antibodies (1/1 corresponds to $10 \mu \mathrm{g}$ antibody) were added and incubated as described above. Values are expressed as mean percentage and range of ${ }^{125} \mathrm{I}$-BSSL bound in the absence of antibodies.

tion by $\beta$-scintillation counting (as an estimate of total cholesterol incorporated into the microvesicles). For determination of cholesterol ester hydrolysis, samples were taken before and after centrifugation and subjected to lipid extraction and thin layer chromatography (TLC). For lipid extraction, aliquots of the pellet were extracted with $1 \mathrm{~mL}$ chloroform/methanol 2:1 (vol/vol), followed by $0.28 \mathrm{~mL}$ water and $0.28 \mathrm{~mL}$ chloroform. After mixing and phase separation, the chloroform phase was collected and dried under nitrogen. The samples were redissolved in $25 \mu \mathrm{L}$ chloroform and applied to a $\left({ }^{19} \mathrm{C}\right)$-silica gel TLC plate $(250 \mu \mathrm{m})$ and the plate developed in heptane/ether/methanol/acetic acid (85/ $30 / 3 / 2, \mathrm{vol} / \mathrm{vol} / \mathrm{vol} / \mathrm{vol}$ ) for separation of free and esterified cholesterol. Standards and samples were visualized by spraying with iodine or running an electronic autoradiography (Instant Imager, Packard Instrument Co., Meriden, CT, U.S.A.). Spots corresponding to free and esterified choles- terol were scraped off from the plate and collected for $\beta$-scintillation counting as an estimate of free and esterified cholesterol, respectively.

To assess cholesterol transport from membrane microvesicles back to donor vesicles, labeled cholesterol donor vesicles (containing $1 \mathrm{pmol}^{3} \mathrm{H}$-cholesterol) were incubated with microvesicle membranes ( $0.1 \mathrm{mg}$ of protein) for $45 \mathrm{~min}$ at $37^{\circ} \mathrm{C}$ and then centrifuged and washed as above. Unlabeled cholesterol donor vesicles and buffer were added to the dispersed final pellet, which was incubated again for 45 min, centrifuged, and washed three times as above, after which the supernatant and pellet was taken to radioactivity determination.

\section{Statistics}

To test the difference between curves the following approach was taken. The relationship between the $\mathrm{y}$ variable and $\mathrm{x}$ variable is a second-degree polynomial where the difference between the curves in the model has been characterized by dummy variables (27). In Figure 2, standard heparin was used as the reference curve. In Figure 3, phospholipid/cholesterol ester donor vesicles without BSSL were used as the reference curve. In Figure 5, a straight line with a y value of $100 \%$ was used as the reference curve. Data were processed using SPSS software from Microsoft (Redmond, WA, U.S.A.).

Applicable values are presented as means $\pm \mathrm{SD}$ (Table 1) or means and range. In several figures, neither mean nor SD or range-are-presented due to the nature of the experiment, i.e. describing a course. All of these experiments have been performed several times with the same principal result but using different microvesicle preparations.

Experiments involving animals was approved by the local ethics committee.

\section{RESULTS}

Binding of BSSL to intestinal membrane microvesicles. BSSL bound in a specific manner to the membrane microvesicles prepared from the mucosal layer of rat small intestine. The fractional binding of labeled BSSL decreased by $>90 \%$ by addition of excess unlabeled BSSL (Fig. $1 A$ ). Furthermore, Fab fragments of polyclonal antibodies added to purified BSSL markedly reduced the binding (Fig. 1B). Cholate, a primary bile salt, which activates the enzyme, did not affect binding in the concentration range of $2-5 \mathrm{mM}$. Treatment of the rat membrane microvesicles with trypsin did not alter binding of BSSL.

Heparin reduced the binding of BSSL to the membrane microvesicles. The effect increased with increasing chain length of the heparin. Standard full-length heparin at a concentration of $0.4 \mu \mathrm{M}$ virtually abolished binding (Fig. 2). Fragments with a mean $M_{\mathrm{r}}$ of $4500 \mathrm{Da}$ was almost as effective, whereas the shortest fragment, with a $M_{\mathrm{r}}$ of 1200 $\mathrm{Da}$, corresponding to a tetramer of alternating glucosamine and uronate monosaccharides, was much less effective in preventing binding. A concentration of $83 \mu \mathrm{M}$ was needed to prevent $50 \%$ of the labeled BSSL from binding compared with $<0.04 \mu \mathrm{M}$ for standard heparin (Fig. 2). Recombinant 


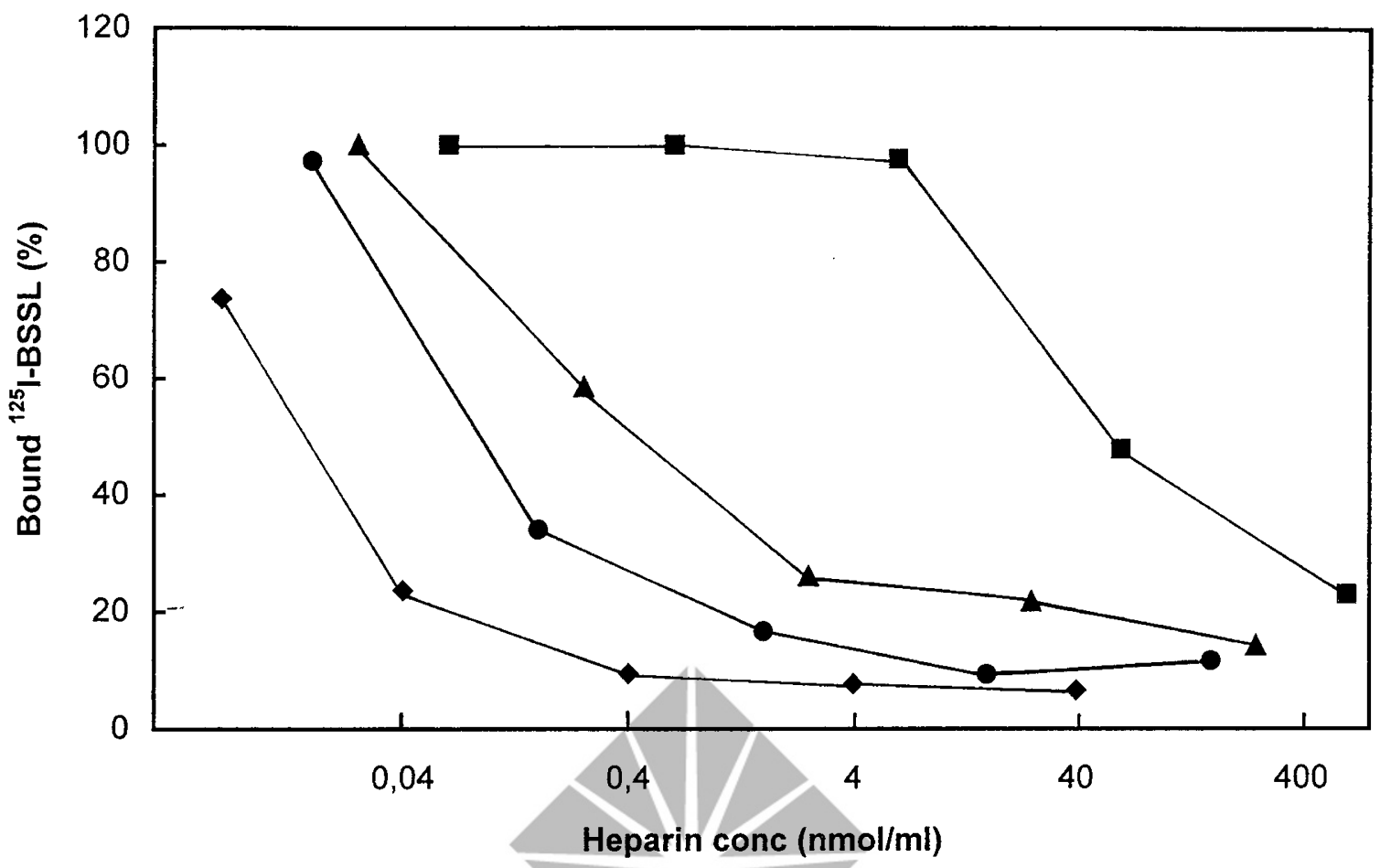

Figure 2. Effect of standard heparin and heparin fragments varying in molecular size on binding of BSSL to intestinal membrane microvesicles. Rat membrane microvesicles were incubated, as described in "Materials and Methods," with $0.5 \mu \mathrm{g}{ }^{125} \mathrm{I}$-BSSL with increasing molar concentrations of standard heparin (filled diamonds) and heparin fragments of different mean $M_{\mathrm{r}}, 1200 \mathrm{Da}$ (filled squares), 2400-3000 Da (filled triangles) or $4500 \mathrm{Da}$ (filled circles). Values are expressed as percent of ${ }^{125} \mathrm{I}$-BSSL bound in the absence of heparin. Significance of the curves are for heparin fragment of $1200 \mathrm{Da}, p<0.001 ; 2400-3000 \mathrm{Da}, p=0.004$, and $4500 \mathrm{Da}$, $p=0.044$, when standard heparin was used as a reference curve. The figure represents a typical experiment of several performed with different microvesicle preparations.

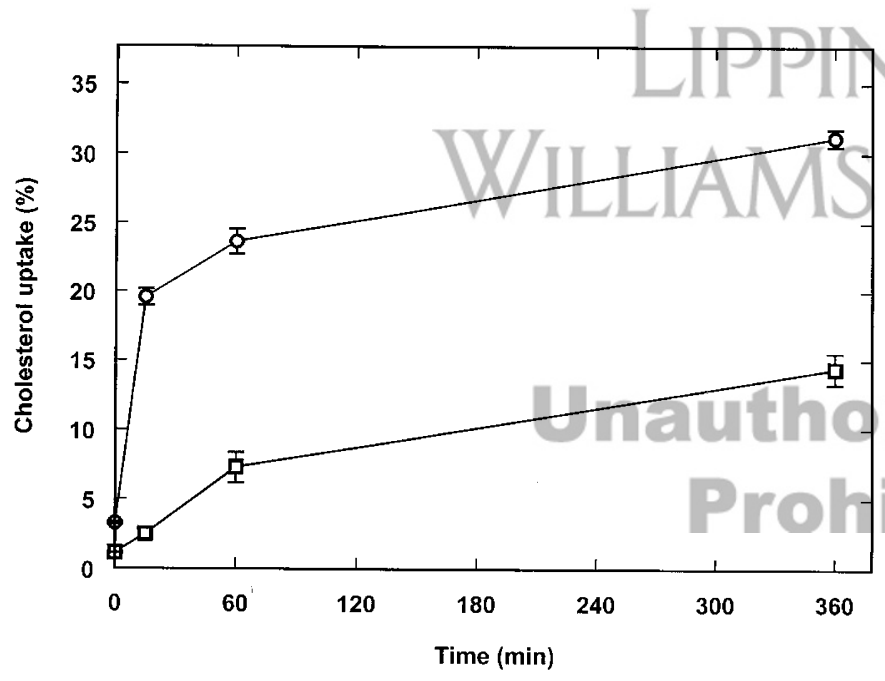

Figure 3. Effect of BSSL on the uptake of cholesterol by intestinal membrane vesicles. Membrane microvesicles were incubated, as described in "Materials and Methods," with cholesterol ester vesicles (containing 0.5 nmol cholesterol ester), with (open circles) or without (open squares) $8 \mu \mathrm{g}$ BSSL for varying times in the presence of $2 \mathrm{mM}$ Na-cholate. The amount of free cholesterol was determined by thin-layer chromatography as described in "Materials and Methods." The values are expressed as mean and range. Significance of the curves was $p=0.029$ when cholesterol ester vesicles without BSSL was used as a reference curve. This experiment is representative for several done, using different microvesicle preparations.

variant B of BSSL also bound effectively to the membranes; in fact, $>10$-fold higher heparin concentration was needed for inhibition compared with native BSSL. At $0.4 \mu \mathrm{M}$ heparin, $>80 \%$ of variant $\mathrm{B}$ remained bound whereas binding of the native enzyme was reduced to $<20 \%$.
Role of BSSL for uptake of cholesterol from phospholipid cholesterol/cholesterol ester donor vesicles. Phospholipid cholesterol or cholesterol ester donor vesicles in the absence of membrane microvesicles was found in the supernatant after centrifugation, indicating a clear separation between donor vesicles and rat microvesicles.

Radiolabeled cholesterol in cholesterol donor vesicles were readily taken up by the intestinal membrane microvesicles. Addition of purified, unlabeled BSSL had no effect on the amount taken up. When heparin was added, alone or in combination with BSSL, the cholesterol uptake remained high (Table 1). If membrane microvesicles already associated with ${ }^{14} \mathrm{C}$-cholesterol were incubated again with unlabeled cholesterol vesicles, $<10 \%$ of the labeled cholesterol was transferred to the unlabeled vesicles (data not shown). These results strongly support the view that the data in Table 1 reflect net transport rather than being merely due to exchange.

Uptake of labeled cholesterol from cholesterol ester donor vesicles into membrane microvesicles was low. In the presence of $2 \mathrm{mM}$ cholate, addition of BSSL enhanced the uptake of labeled cholesterol several-fold (Fig. 3). The uptake increased with increasing concentrations of BSSL (Fig. 4). Thin-layer chromatography carried out on samples taken before and after separation of donor vesicles from membrane microvesicles showed that almost only free cholesterol was found in the membrane microvesicles. From samples containing both donor and membrane microvesicles, it was possible to calculate the degree of hydrolysis of cholesterol ester under the conditions 
Table 1. Effect of BSSL, heparin, and bile salt on uptake of unesterified cholesterol by intestinal membrane microvesicles

\begin{tabular}{ll}
\hline \multicolumn{1}{c}{ Addition } & Uptake $(\%)$ \\
\hline None & $56.9 \pm 4.1^{*}$ \\
BSSL & $56.6 \pm 1.5 \dagger$ \\
BSSL + cholate & $58.3 \pm 2.1^{*}$ \\
BSSL + cholate + heparin & $58.3 ; 63.1 \ddagger$ \\
\hline
\end{tabular}

Labeled phospholipid/cholesterol donor vesicles were incubated with rat intestinal membrane microvesicles for $60 \mathrm{~min}$ in the presence or absence of BSSL $(8.6 \mu \mathrm{g})$, cholate $(2 \mathrm{mM})$, and heparin $(1 \mathrm{mg} / \mathrm{mL})$ as described in "Materials and Methods." Uptake refers to percentage of totally available labeled cholesterol. Number of experiments: *six, †three, and two (both values presented).

used. As shown in Figure 4, the extent of hydrolysis at different BSSL concentrations paralleled the incorporation of labeled cholesterol into the intestinal membrane microvesicles.

Hydrolysis of cholesterol esters by BSSL was not dependent on the presence of membrane microvesicles. Labeled cholesterol ester donor vesicles alone served as a good substrate for BSSL, and, with increasing concentrations of BSSL, hydrolysis of cholesterol ester also increased (data not shown). To test whether binding of BSSL to the membrane microvesicles in any way affected the hydrolysis of cholesterol esters, the same experiment as described in Figure 4 was carried out, but in presence of heparin (Fig. 5). Addition of increasing concentrations of heparin resulted in decreasing amount of cholesterol in the intestinal membrane microvesicles (Fig. 5A). This decrease paralleled inhibition of cholesterol ester hydrolysis with increasing heparin concentration (Fig. 5B). It should be noted, however, that the concentration of heparin needed to inhibit cholesterol ester hydrolysis was orders of magnitude higher

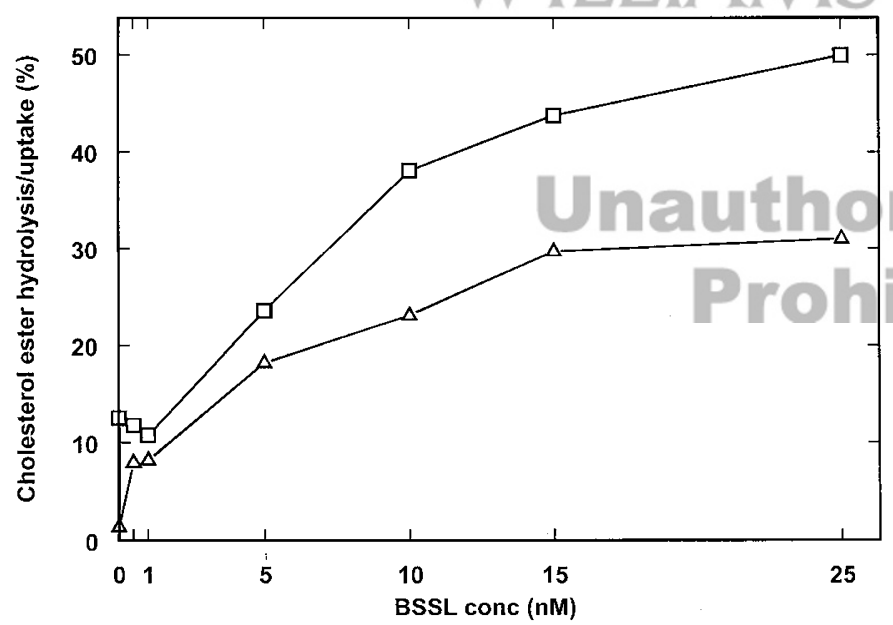

Figure 4. Effect of BSSL concentration on hydrolysis of cholesterol ester vesicles and on uptake of cholesterol by intestinal membrane microvesicles. Membrane microvesicles were incubated as described in "Materials and Methods" with cholesterol ester donor vesicles and increasing concentrations of BSSL for $1 \mathrm{~h}$ of $37^{\circ} \mathrm{C}$ in the presence of $2 \mathrm{mM} \mathrm{Na-cholate.} \mathrm{Percentage}$ hydrolysis (open squares) was assessed by measuring labeled free cholesterol by $\beta$-scintillation. Uptake (open triangles) of cholesterol by membrane microvesicles was determined by $\beta$-scintillation after separation of free and esterified cholesterol by thin-layer chromatography. Values are expressed as percentage of bound, labeled cholesterol ester in the absence of BSSL. The plot represents a typical experiment. Similar experiments but with different microvesicle preparations gave the same principal results. than that required to reduce binding of BSSL to the intestinal membrane microvesicles (cf. Figs. 2 and 4). Inhibition of BSSL activity by heparin is not a general phenomenon because heparin had only marginal effect on the activity when an emulsion of long-chain triacylglycerols was used as substrate for BSSL (Fig. $5 B$ ).

\section{DISCUSSION}

The BSSL and pancreatic colipase-dependent lipase have both been suggested to bind to a receptor, or receptor-like structure, on enterocytes $(10-12)$. There is evidence to suggest that binding to the tentative receptor involves interaction with heparin or a heparin-like structure. In a recent study, we showed that the two lipases have different affinities for heparin in vitro and that such receptor binding could be of relevance for BSSL in vivo but hardly for pancreatic colipase-dependent lipase (28). A possible relevance of receptor binding would be to facilitate uptake of lipolytic products by directing lipolysis

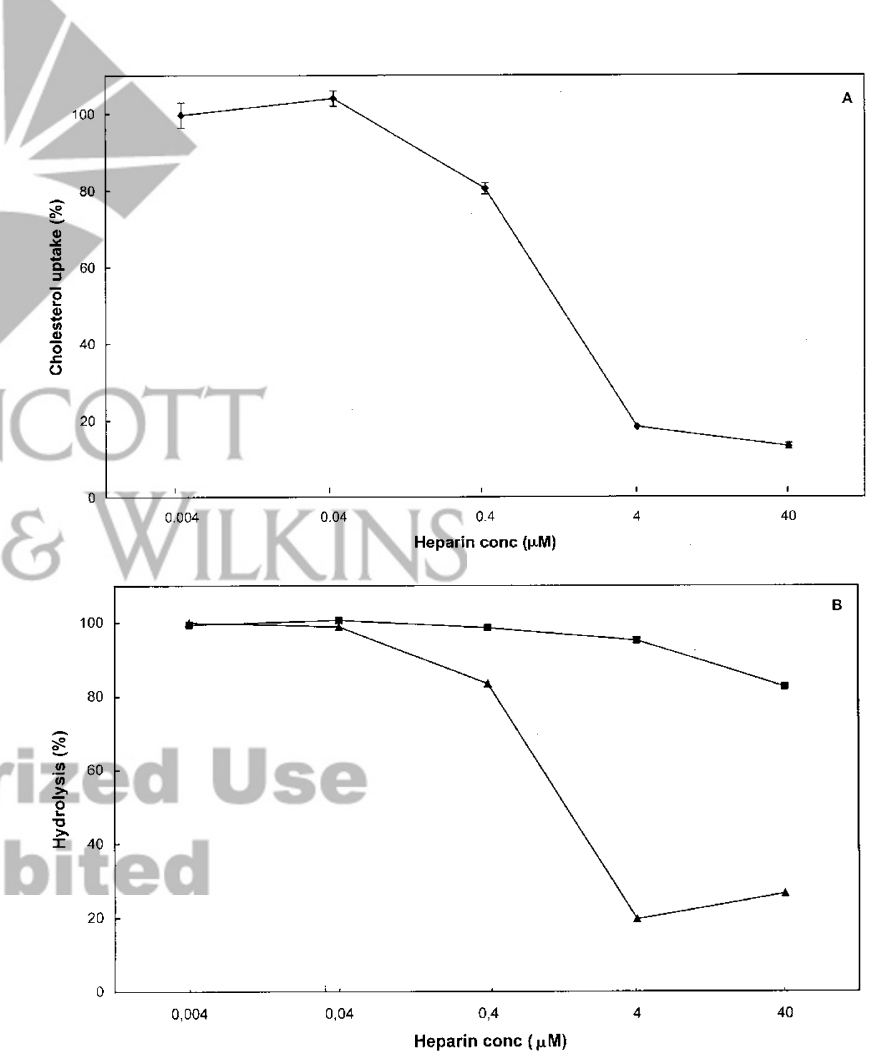

Figure 5. Effect of heparin on hydrolysis and uptake of cholesterol from phospholipid/cholesterol ester donor vesicles by intestinal membrane microvesicles. Rat membrane microvesicles $(0.1 \mathrm{mg}$ of protein) were incubated for $45 \mathrm{~min}$ at $37^{\circ} \mathrm{C}$ with $0.5 \mathrm{nmol}$ cholesterol ester donor vesicles, $2 \mathrm{mM}$ Na-cholate, $8 \mu \mathrm{g}$ BSSL, and increasing concentrations of standard heparin (see "Materials and Methods"). (A) Uptake of cholesterol determined after separation of membrane microvesicles, thin-layer chromatography, and $\beta$-scintillation. Values are expressed as percentage of bound, labeled cholesterol ester vesicles in the absence of heparin (mean and range). $(B)$ Effect of heparin on hydrolysis of emulsified triacylglycerol (filled squares) and of cholesterol ester in phospholipid/cholesterol ester donor vesicles (filled triangles), respectively. Activity measurements were carried out as described in "Materials and Methods." Values are expressed as percentage of respective activity in the absence of heparin. Using a straight line as reference, triglyceride hydrolysis did not deviate significantly $(p=0.719)$, whereas cholesterol ester hydrolysis did ( $p=$ 0.022). The figure depicts one typical experiment. 
close to the absorptive cells $(10,12)$. This could be of particular importance under condition of low intraluminal bile salt concentration and limited capacity to solubilize and transport lipolysis products, e.g. in the neonatal period $(29,30)$. In addition to its role in hydrolysis of dietary lipid substrates, e.g. acylglycerols, cholesterol esters, retinol esters (31), and ceramides (32), BSSL has been proposed to act as a transport protein, directly facilitating uptake of free cholesterol when bound to the receptor $(11,33)$.

In the present study, we confirm that BSSL binds to intestinal membrane microvesicles and that antibodies to BSSL block the binding. We further show that the binding is prevented by excess, free heparin in the medium. The ability of heparin to prevent binding of the enzyme to the membrane was dependent on its molecular mass. A heparin fragment with a molecular size of about $1200 \mathrm{Da}$ was almost ineffective; about 1000 -fold higher concentration than of standard heparin was needed for preventing binding of BSSL. These results are in complete agreement with previous results on binding of BSSL to immobilized heparin (28). The fact that the binding persisted when the membrane microvesicle preparation was pretreated with trypsin, degrading most of the membrane protein, supports the view that a carbohydrate moiety is an essential constituent of a receptor structure. Although, a proteoglycan from the Caco-2 cell-line has been partially characterized and suggested to be the BSSL receptor (34), further characterization has not yet been made.

A general view is that the heparin-binding region of BSSL resides in the $\mathrm{N}$-terminal part of the enzyme $(23,28,35,36)$. This view has, however, been questioned. Spilburg et al. (37) suggested that the C-terminal repeat part is involved in the heparin interaction and Wang et al. (38) speculated that this part confers adhesive properties to the enzyme. Our observation that a recombinant variant of BSSL (variant B), lacking all the C-terminal repeats, bound to the intestinal membrane microvesicles more strongly than native enzyme, clearly supports the former view.

Hypothetically, if BSSL is important in promoting absorption of cholesterol, this could be particularly important during the neonatal period when the need for cholesterol for membrane synthesis is comparatively high (4), and the capacity for endogenous synthesis may not be fully developed in analogy to what has been shown for LCPUFA (1). If so, the comparably high cholesterol content in human milk could be beneficial for the developing brain, provided that it is efficiently used. Breastfed infants do have higher serum cholesterol levels than infants fed ordinary cow milk-based infant formula with lower cholesterol content than human milk (6). When comparing breastfed infants with infants fed experimental formula supplemented with cholesterol to the level of human milk, breast-fed infants tended to have higher total serum cholesterol, whereas the endogenous fractional synthetic rate was lower than in the formula fed group $(39,40)$. This suggests that absorption may have been more effective in the breast-fed infants, or that other factors than the cholesterol concentration in milk affects cholesterol metabolism in breast-fed infants. It is tempting to speculate that this could program the metabolism toward lower cholesterol synthesis rate later in life when the requirement for cholesterol for membrane formation is comparatively lower. This hypothesis would in fact bear some support from our observation that adolescents with short duration of breast feeding $(<6 \mathrm{mo})$ or early introduction of infant formula had higher mean total serum cholesterol than those who had been breast-fed for a longer period (41).

Our data do not confirm the view that BSSL acts as a cholesterol transporter in the intestine as was postulated (11, 33). The presence of BSSL had no effect on uptake of unesterified cholesterol into the intestinal membrane microvesicles. This is in agreement with previous studies using Caco-2 cells $(16,17)$. From studies in gene-targeted mice, it was concluded that BSSL has an effect on absorption of cholesterol esters but not on free cholesterol $(14,15)$.

When cholesterol was added in esterified form, BSSL had a profound effect on cholesterol uptake. However, the incorporation of cholesterol into the membrane microvesicles paralleled the extent of hydrolysis of cholesterol esters, strongly suggesting that hydrolysis was the rate-limiting step for cholesterol uptake. Including heparin in this system in amounts well exceeding those required to inhibit binding of BSSL to the microvesicles clearly reduced the amount of cholesterol taken up by the membrane microvesicles. This was, however, due to an effect on hydrolysis itself rather than on uptake of released cholesterol. Direct measurement showed that BSSL activity against cholesterol esters was inhibited by heparin. The nature of this inhibition is unclear. With emulsified long-chain triacylglycerols as substrate, no similar inhibition was seen with comparable concentrations of heparin.

We conclude that BSSL has a role in the utilization of dietary cholesterol but solely by hydrolyzing cholesterol esters to absorbable free cholesterol and fatty acids, and not in capacity of being a cholesterol transporter. However, BSSL may also contribute to efficient cholesterol absorption by its general promoting effect on fat digestion and absorption and, perhaps after binding to the enterocytes, by directing part of fat digestion to the mucosal surface. This could facilitate absorption, particularly in situations of low intraluminal bile salt concentrations, e.g. the newborn infant, of lipolysis products particularly dependent on bile salts for micellar solubilization and absorption such as cholesterol (29). It should be noted that the specific activity of BSSL in vitro against cholesterol esters is considerably lower than the activity against other substrates, e.g. emulsified triacylglycerol (21). Our data show that the cholesterol ester hydrolyzing activity of BSSL is not affected by binding to a tentative membrane receptor. Hence, any physiologic significance of the receptor binding requires further studies. In addition, it is still not known what fraction of BSSL, present in the intestinal lumen, is associated to the tentative receptor under fat digestion in vivo, or how abundant receptors are at different levels of the small intestine.

Acknowledgment. The authors thank Eva-Lotta Vestman for excellent technical assistance. 


\section{REFERENCES}

1. Aggett PJ, Haschke F, Heine W, Hernell O, Koletzko B, Launiala K, Rey J, Rubino A, Schöch G, Senterre J, Tormo R 1991 Comment on the content and composition of lipids in infant formulas. ESPGAN Committee on Nutrition. Acta Paediatr Scand $80: 887-96$

2. Agostoni C, Marangoni F, Bernardo L, Lammardo AM, Galli C, Riva E 1999 Long-chain polyunsaturated fatty acids in human milk. Acta Paediatr Suppl 88:68-71

3. Hernell O 1990 The requirements and utilization of dietary fatty acids in the newborn infant. Acta Paediatr Scand Suppl 365:20-27

4. Clandinin MT 1999 Brain development and assessing the supply of polyunsaturated fatty acid. Lipids 34:131-137

5. Koletzko B, Agostoni C, Carlson SE, Clandinin T, Hornstra G, Neuringer M, Uauy R, Yamashiro Y, Willatts P 2001 Long chain polyunsaturated fatty acids (LC-PUFA) and perinatal development. Acta Paediatr 90:460-464

6. Wong WW, Hachey DL, Insull W, Opekun AR, Klein PD 1993 Effect of dietary cholesterol on cholesterol synthesis in breast-fed and formula-fed infants. J Lipid Res 34:1403-1411

7. Thomson AB 1980 Unidirectional flux rate of cholesterol and fatty acids into the intestine of rats with drug-induced diabetes mellitus: effect of variations in the effective resistance of the unstirred water layer and the bile acid micelle. J Lipid Res 21:687-698

8. Thurnhofer H, Hauser H 1990 Uptake of cholesterol by small intestinal brush border membrane is protein-mediated. Biochemistry 29:2142-2148

9. Berge KE, Tian H, Graf GA, Yu L, Grishin NV, Schultz J, Kwiterovich P, Shan B, Barnes R, Hobbs HH 2000 Accumulation of dietary cholesterol in sitosterolemia caused by mutations in adjacent ABC transporters. Science 290:1771-1775

10. Bosner MS, Gulick T, Riley DJ, Spilburg CA, Lange LGD 1988 Receptor-like function of heparin in the binding and uptake of neutral lipids. Proc Natl Acad Sci U S A 85:7438-7442

11. Lopez-Candales A, Bosner MS, Spilburg CA, Lange LG 20891993 Cholesterol transport function of pancreatic cholesterol esterase: directed sterol uptake and esterification in enterocytes. Biochemistry 32:12085-12089

12. Bosner MS, Gulick T, Riley DJ, Spilburg CA, Lange LG 1989 Heparin-modulated binding of pancreatic lipase and uptake of hydrolyzed triglycerides in the intestine. J Biol Chem 264:20261-20264

13. Bell Jr CC, Swell L 1968 Effect of total pancreatectomy on cholesterol absorption and the serum cholesterol level in man. Proc Soc Exp Biol Med 128:575-577

14. Weng W, Li L, van Bennekum AM, Potter SH, Harrison EH, Blaner WS, Breslow JL, Fisher EA 1999 Intestinal absorption of dietary cholesteryl ester is decreased but retinyl ester absorption is normal in carboxyl ester lipase knockout mice. Biochemistry $38: 4143-4149$

15. Howles PN, Carter CP, Hui DY 2021996 Dietary free and esterified cholesterol absorption in cholesterol esterase (bile salt-stimulated lipase) gene-targeted mice. J Biol Chem 271:7196-7197

16. Huang Y, Hui DY 1990 Metabolic fate of pancreas-derived cholesterol esterase in intestine: an in vitro study using Caco-2 cells. J Lipid Res 31:2029-2037

17. Shamir R, Johnson WJ, Zolfaghari R, Lee HS, Fisher EA 1995 Role of bile salt-dependent cholesteryl ester hydrolase in the uptake of micellar cholesterol by intestinal cells. Biochemistry 34:6351-6358

18. Mackay K, Starr JR, Lawn RM, Ellsworth JL 1997 Phosphatidylcholine hydrolysis is required for pancreatic cholesterol esterase- and phospholipase A2-facilitated cholesterol uptake into intestinal Caco-2 cells. J Biol Chem 272:13380-13389

19. Nielsen JI, Østergaard P 1988 Chemistry of heparin and low molecular weight heparin. Acta Chir Scand Suppl 543:52-56

20. Kristensen HI, Tromborg EM, Nielsen JR, Nielsen JI, Johansen KB, Østergaard PB 1991 Development and validation of a size exclusion chromatography method for determination of molecular masses and molecular mass distribution in low molecular weight heparin. Thromb Res 64:131-141
21. Bläckberg L, Hernell O 1981 The bile-salt-stimulated lipase in human milk. Purification and characterization. Eur J Biochem 116:221-225

22. Hansson L, Bläckberg L, Edlund M, Lundberg L, Strömqvist M, Hernell O 1993 Recombinant human milk bile salt-stimulated lipase. Catalytic activity is retained in the absence of glycosylation and the unique proline-rich repeats. J Biol Chem 268:26692-26698

23. Bläckberg L, Strömqvist M, Edlund M, Juneblad K, Lundberg L, Hansson L, Hernell O 1995 Recombinant human-milk bile-salt-stimulated lipase. Functional properties are retained in the absence of glycosylation and the unique proline-rich repeats. Eur J Biochem 228:817-821

24. Wallinder L, Peterson J, Olivecrona T, Bengtsson-Olivecrona G 1984 Hepatic and extrahepatic uptake of intravenously injected lipoprotein lipase. Biochim Biophys Acta 795:513-524

25. Davidson LA, Lönnerdal B 1988 Specific binding of lactoferrin to brush-border membrane: ontogeny and effect of glycan chain. Am J Physiol 254:G580-G585

26. Dahlqvist A 1964 Method for assay of intestinal disaccharides. Anal Biochem $7: 18-25$

27. Polissar L, Diehr P 1982 Regression analysis in health services research: the use of dummy variables. Med Care 20:959-966

28. Fält H, Hernell $\mathrm{O}$, Bläckberg L 2001 Do bile salt-stimulated lipase and colipasedependent lipase share a common heparin-containing receptor? Arch Biochem Biophys 386:188-194

29. Hernell O, Staggers JE, Carey MC 1990 Physical-chemical behavior of dietary and biliary lipids during intestinal digestion and absorption. 2. Phase analysis and aggregation states of luminal lipids during duodenal fat digestion in healthy adult human beings. Biochemistry 29:2041-2056

30. Halpern Z, Vinograd Z, Laufer H, Gilat T, Moskowitz M, Bujanover Y 1996 Characteristics of gallbladder bile of infants and children. J Pediatr Gastroenterol Nutr 23:147-150

31. Fredrikzon B, Hernell O, Blackberg L, Olivecrona T 1978 Bile salt-stimulated lipase in human milk: evidence of activity in vivo and of a role in the digestion of milk retinol esters. Pediatr Res 12:1048-1052

32. Nyberg L, Farooqi A, Blackberg L, Duan RD, Nilsson A, Hernell O 1998 Digestion of ceramide by human milk bile salt-stimulated lipase. J Pediatr Gastroenterol Nutr 27:560-567

33. Myers-Payne SC, Hui DY, Brockman HL, Schroeder F 1995 Cholesterol esterase: a cholesterol transfer protein. Biochemistry 34:3942-3947

34. Bosner MS, Colwell NS, Haagen H, Spilburg CA, Lange LG 1994 Purification and partial characterization of the human intestinal receptor for pancreatic cholesterol esterase. Circulation 90:I405

35. Hernell O, Bläckberg L 1991 Digestion and absorption of human milk lipids. In: Dulbecco R (ed) Encyclopedia of Human Biology. Academic Press, New York, pp 47-56

36. Moore SA, Kingston RL, Loomes KM, Hernell O, Bläckberg L, Baker HM, Baker EN 2001 The structure of truncated recombinant human bile salt-stimulated lipase reveals bile salt-independent conformational flexibility at the active-site loop and provides insights into heparin binding. J Mol Biol 312:511-523

37. Spilburg CA, Cox DG, Wang X, Bernat BA, Bosner MS, Lange LG 1995 Identification of a species specific regulatory site in human pancreatic cholesterol esterase. Biochemistry 34:15532-15538

38. Wang CS, Dashti A, Jackson KW, Yeh JC, Cummings RD, Tang J 1995 Isolation and characterization of human milk bile salt-activated lipase C-tail fragment. Biochemistry 34:10639-10644

39. Cruz ML, Wong WW, Mimouni F, Hachey DL, Setchell KD, Klein PD, Tsang RC 1994 Effects of infant nutrition on cholesterol synthesis rates. Pediatr Res 35:135-140

40. Bayley TM, Alasmi M, Thorkelson T, Krug-Wispe S, Jones PJ, Bulani JL, Tsang RC 1998 Influence of formula versus breast milk on cholesterol synthesis rates in four-month-old infants. Pediatr Res 44:60-67

41. Bergström E, Hernell O, Persson LA, Vessby B 1995 Serum lipid values in adolescents are related to family history, infant feeding, and physical growth. Atherosclerosis $117: 1-13$ 